\title{
Statins and Sepsis Literature Review
}

\author{
Alicia Hernández Torres ${ }^{1}$, Ana Belén Hernández Cascales ${ }^{2}$, Pedro Pujante Alarcón ${ }^{2}$, \\ Alfonso López Ruiz ${ }^{3}$, María Ángeles Ibáñez Gil ${ }^{4}$, María Dolores Hellín Gil ${ }^{2}$

\begin{abstract}
${ }^{1}$ Hospital University Virgen de la Arrixaca de Murcia, Murcia, Spain; ${ }^{2}$ Hospital University Virgen de la Arrixaca de Murcia, Murcia, Spain; ${ }^{3}$ Pharmaceutical Care Research at the University of Granada, Granada, Spain; ${ }^{4}$ Health Center Mariano Yago, Murcia, Spain.
\end{abstract} \\ Email: lablilly@gmail.com
}

Received September $8^{\text {th }}, 2013$; revised October $12^{\text {th }}, 2013$; accepted October $21^{\text {st }}, 2013$

Copyright (C) 2013 Alicia Hernández Torres et al. This is an open access article distributed under the Creative Commons Attribution License, which permits unrestricted use, distribution, and reproduction in any medium, provided the original work is properly cited.

\begin{abstract}
Recent data suggest that, in addition to improving dyslipidemia, statin may reduce the risk of infections and infectionrelated complications. The aim of this study is to make a review of the literature about the effects of statins on clinically relevant outcomes of patients admitted to the hospital and having an infection and/or sepsis, principally in terms of intensive care unit admissions and related death.
\end{abstract}

Keywords: Statins; Pravastatin; Simvastatin; Sepsis; Bacteremia; Mortality

\section{Introduction}

The hallmark of sepsis syndrome is an intense inflammatory response, which reflects a delicate interaction between the extensive activation of host defense mechanisms and direct and indirect effects of the invading microorganisms and their toxins. As a result, a number of important abnormalities occur during sepsis, including endothelial dysfunction and apoptosis, activation and increased production of cytokines and other proinflammatory mediators, activation and extravascular transmigration of leukocytes, and activation of platelets and coagulation and complement systems [1-3]. For this reason, because numerous cascades are triggered during sepsis, selective blocking of inflammatory mediators may be insufficient to arrest this process [4].

Recent studies have demonstrated a wide variety of statin properties independent of their lipid-lowering ability [5-8]. Statins inhibit 3-hydroxy-3 methylgutaryl coenzyme A (HMG CoA) reductase, were developed as lipid level-lowering agents, and have been studied extensively in relation to atherosclerosis. However, statins not only reduce cholesterol level but also decrease the levels of intermediate products of cholesterol synthesis, principally mevalonate, precursor of a lot of isoprenoids which play a crucial role in several intracellular signaling pathways in inflammatory response. Apparently, this effect is the major explanation for the observed pleiotropic effects of statins, which include the modulation of both innate and adaptative immune system, antiinflammatory effects, the direct activation of heme oxygenase, direct interference in leucocyte-endothelial interactions, with limitations of the activation of endothelial cells and improvement of endothelial function, up-regulation of endothelial nitric oxide synthase and direct inhibition of major histocompatibility complex class II (MHCII), counteraction of the deleterious effects of sepsis on the coagulation system by inhibiting tissue factor expression and reducing prothrombin fragment levels and by strongly increasing the expression of thrombomodulin [9-12]. Moreover, they have direct effects on pathogenic microorganisms, such as Salmonella typhimurium, HIV, CMV ordifferent fungi species [13-15]. Such anti-inflamatory, antioxidant, inmunomodulatory, and antiapoptotic features have been collectively referred to as pleiotropic effects [4].

\section{Effects of the Use of Statins in Sepsis Markers}

All of us known the effect of the statins in the reduction of pro-inflammatory cytoquines, as have been demonstrated in a randomized and prospective study comparing simvastatin to placebo, where there was a significant reduction in tumor necrosis factor alpha (TNF- $\alpha)$ and interleukin 6 (IL-6) in the statin group [16]. The same effect was demonstrated with atorvastatin in a study with septic rats; it showed that atorvastatin improves survival in septic rats, decreases circulating inflammatory cyto- 
kines, attenuating higher levels of IL- 6 and TNF- $\alpha$, and improves insulin resistance. If we take into account that, in septic patients, insulin resistance is accompanied by a reduction in the insulin-induced Akt (proteina kinase B) phosphorylation in liver, muscle and adipose tissue, and that this protein plays an important role in the protection against apoptosis, it is possible that the reduced insulin signaling through this pathway, in sepsis, may contribute to multiorgan failure by preventing or delaying apoptosis [17]. It seems that statins can have a protector activity in yeast sepsis; we know that yeast use the same HMG CoA reductase as humans, however, their end-product is ergosterol rather than colesterol [18]; probably, this is the explanation of why simvastatin inhibit the growth of different species of Candida [19], independently of the effect in the reduction of pro-inflammatory cytokines. The population-based cohort study performed by Thomsen et al. C-reactive protein levels at admisión tended to be lower in statin users than in non users, perhaps because of the antiinflammatory effects of statins [20].

\section{Clinical Effects of Statins in Sepsis}

Many, but not all studies, have demonstrated the benefits of statins in patients with sepsis [21]. Liappis et al. demonstrated that patients on statins had greater than 7 times greater chance of survival with sepsis [22]. Almog et al. showed in an ICU that only $2.4 \%$ of patients on a statin developed bacterial sepsis compared with 19\% ( $\mathrm{p}<$ 0.001 ) who were no at statin [23]. Gupta et al. also found that hemodiálisis patients taking statins were also significantly less likely to be hospitalizad for severe sepsis [24], and Van de Garde et al. showed a significant reduction of the risk of pneumonia among patients with diabetes mellitus [25]. Kruger et al. studied a cohort of bacteriemic patients and found a significantly lower incidence of mortality and bacteraemia-related mortality with statin therapy [26]. There have been several other retrospective observational studies with similar findings with bacteremia. Also, statins reduce the risk of nosocomial sepsis among patients hospitalized for acute coronary syndrome, ischemic stroke, or revascularization [27], and the risk of infection-related mortality among patients with atherosclerotic disease [28]. Furthermore, in patients with sepsis [29], bacteremia [30] or communityacquired pneumonia [31] and in patients admitted to the intensive care unit with Acute Physiology and Chronic Health Evaluation II scores of $\geq 20$ [32], statins prevented sepsis from becoming severe or decreased 28-day, 30day, or 31 - 180-day mortality, hospital mortality, or bacteremia-related mortality. Al Harbi et al. found that statin therapy in critically ill patiens (specially those elderly, diabetics, patient with higuer severity of illness, with a low GCS, with several sepsis or with simvastatin) had a lower hospital mortality [33]. Statins also improved mortality among patients with angiographically defined coronary artery stenosis $>70 \%$ and with concurrent cytomegalovirus seroposivity and high C-reactive protein levels. Patiens who received statins had a lower risk of death due to influenza, pneumonia, or chronic obstructive pulmonary disease in one study [34] and a lower risk of fatal pneumonia in another study [35]. In another hand, in a study which compared the outcomes of inmunocompromised patients who received or not statins, the prior use of them was not associated with an increase of the survival [36]. Other investigations haven't demonstrated benefits with statins in patients with sepsis, as Fernandez et al., who found that the hospital mortality was even higher in patients receiving statins and mechanical ventilation [37], or Yang et al. [38] who conducted a retrospective study and found no differences in mortality between the two groups. However, Kopterides et al., in a critical review of 22 studies with 177,260 patients (7 prospective cohorts, 12 retrospective cohorts and 1 aleatorized clinic assay), concluded that the majority of studies show that statins have a beneficial effect over the result of the infection; nevertheless, its observational design don't let us to get firm conclusions [39].

Similar effects have been demonstrated with candidiasis. The beneficial effect in the reduction of mortality in patients admitted to an ICU with candidemia associated to a systemic inflammatory response syndrome, was demonstrated in the study performed by Forrest et al. [40], although the reduction in mortality wasn't statistically significant in the multivariant analysis. In this study, the reduction of the inflammatory response in comparation with the control group, is probably due to the effects of statins in the production of cytokines and ergosterol.

Evaluating the effects of statins in sepsis caused by concrete microorganisms, we can observe how, in a clinical study, patients who received statins had significantly lower overall and attributable mortality associated with bacteremic infections caused by gram-negative bacilli and $S$. aureus than did those not receiving statins. Simvastatin demonstrated a statistically significant antimicrobial effect against methicillin-susceptible $S$. $a u$ reus and, to a lesser extent, against methicillin-resistant $S$. aureus. Fluvastatin also showed a statistically significant but less marked antimicrobial effect, compared with that of simvastatin. Moreover, fluvastatin might have a potential role in the treatment of tuberculosis as a result of the enhacement of the host T-helper response agaisnt $M$. tuberculosis. In relation to fungi, we can see that statins show antifungal activity against Candida species; they inhibit the growth of Candida by decreasing the ergosterol levels. It seems that lovastatin with fluconazole and fluvastatin with fluconazole or itraconazole had synergistic effects on Candida species, whereas pravastatin or fluvastatin with fluconazol haven't demonstrated these 
effects. The combination of amphotericin B and fluvastatin had additive effects, too. Different statins have demonstrated activity against zygomycetes, Aspergillus, C. neoformans, or viruses as cytomegalovirus, EpsteinBarr virus or HIV [41].

\section{Are Statins Indicated in the Treatment of Septic Patients?}

The timing of initiation of statins with regards to the onset of sepsis is still being determined. This is because it takes several days for statins to achieve desiderable concentrations [42]. Moreover, the majority of patients who are statin-users don't receive statins after the admission, because of the lack of intravenous formulation, although recent data suggest that this method may lead to elevated plasma levels of the statins [43]. Pre-admission use of a statin has shown relative risk reductions in large cohort studies evaluating community acquired pneumonia and ICU admission [20,44]. Thomsen et al. showed that the use of preadmisión statin up to 180 days prior to admission demonstrated a $25 \%-30 \%$ mortality rate reduction at 90 days [20]. Also, Christensen et al. showed about a $20 \%$ mortality rate reduction between statin users and non users [44]. However, Majumdar et al. showed in a prospective cohort study for pneumonia that the benefit of statins disappeared after adjustment for confounders [45]. We will need, because of all these reasons, more exhaustive studies to be able to make conclusions.

\section{Conclusion}

Our review suggests that statin use is associated with a beneficial effect in treating and preventing different infections. Further studies are warranted to define the optimal dose of statin and timing of therapy in a prospective manner.

\section{REFERENCES}

[1] J. C. Marshall, "Sepsis: Current Status, Future Prospects," Current Opinion in Critical Care, Vol. 10, No. 4, 2004, pp. 250-264. http://dx.doi.org/10.1097/01.ccx.0000134877.60312.f3

[2] M. Terblanche, Y. Almog, R. S. Ronsenson, T. S. Smith and D. G. Hackam, "Statin: Panacea for Sepsis?" Lancet Infectious Diseases, Vol. 6, No. 4, 2006, pp. 242-248. http://dx.doi.org/10.1016/S1473-3099(06)70439-X

[3] I. M. Tleyjeh, T. Kashour, F. A. Hakim and V. A. Zimmerman, P. J. Erwin, et al., "Statins for the Prevention and Treatment of Infections. A Systematic Review and Meta-Analysis," Archives of Internal Medicine, Vol. 169, No. 18, 2009, pp. 1658-1667. http://dx.doi.org/10.1001/archinternmed.2009.286

[4] I. Kouroumichakis, N. Papanas, S. Proikaki, P. Zarogoulidis and E. Maltezos, "Statins in Prevention and Treatment of Severe Sepsis and Septic Shock," European
Journal of Internal Medicine, Vol. 22, No. 2, 2011, pp. 125-133. http://dx.doi.org/10.1016/j.ejim.2010.12.004

[5] G. Weitz-Schmidt, "Statins as Anti-Inflammatory Agents," Trends in Pharmacological Sciences, Vol. 23, No. 10, 2002, pp. 482-486. http://dx.doi.org/10.1016/S0165-6147(02)02077-1

[6] L. M. Blanco-Colio, J. Tunon, J. L. Martin-Ventura and J. Egido, "Antiinflammatory and Inmunomoduladory Effects of Statins," Kidney International, Vol. 63, 2003, pp. 12-23.

http://dx.doi.org/10.1046/j.1523-1755.2003.00744.x

[7] M. Terblanche, Y. Almog, R. S. Rosenson, T. S. Smith and D. G. Hackman, "Statins and Sepsis: Multiple Modifications at Multiple Levels," Lancet Infectious Diseases, Vol. 7, No. 5, 2007, pp. 358-368. http://dx.doi.org/10.1016/S1473-3099(07)70111-1

[8] C. P. Martin, R. L. Talbert, D. S. Burgess and J. I. Peters, "Effectiveness of Statins in Reducing the Rate of Severe Sepsis: A Retrospective Evaluation," Pharmacotherapy, Vol. 27, No. 1, 2007, pp. 20-26.

[9] B. Zingarelli, "Nuclear Factor-Kappa B," Critical Care Medicine, Vol. 33, No. 12, 2005, pp. s414-s416. http://dx.doi.org/10.1097/01.CCM.0000186079.88909.94

[10] M. E. Falagas, C. G. Makris, D. K. Mstthaiou and P. I. Rafailidis, "Statins for Infection and Sepsis: A Systematic Review of the Clinical Evidence," Journal of Antimicrobial Chemotherapy, Vol. 61, No. 4, 2008, pp. 774-785. http://dx.doi.org/10.1093/jac/dkn019

[11] L. Kronmann, C. Hatfield and K. Kronmann, "Statin Therapy: Not Just Used to Lower Cholesterol?" Critical Care Nurse, Vol. 30, No. 2, 2007, pp. 154-160.

[12] S. Steiner, W. S. Speidl, J. Pleiner, et al., "Simvastatin Blunts Endotoxin-Induced Tissue Factor in Vivo," Circulation, Vol. 111, No. 14, 2005, pp. 1841-1846. http://dx.doi.org/10.1161/01.CIR.0000158665.27783.0C

[13] G. Del Real, S. Jiménez-Baranda, E. Mira, et al., "Statins Inhibit HIV Infection by Down-Regulating Rho Activity," Journal of Experimental Medicine, Vol. 200, No. 4, 2004, pp. 541-547. http://dx.doi.org/10.1084/jem.20040061

[14] M. W. Merx, E. A. Liehn, U. Janssens, et al., "HMGCoA Reductase Inhibitor Simvastatin Profoundly Improves Survival in a Murine Modelo Os Sepsis," Circulation, Vol. 109, No. 21, 2004, pp. 2560-2565. http://dx.doi.org/10.1161/01.CIR.0000129774.09737.5B

[15] A. Gyetvai, T. Emri, K. Takács, et al., "Lovastatin Posesses a Fungistatic Effect against Candida albicans, but Does Not Trigger Apoptosis in This Opportunistic Human Patogen," FEMS Yeast Research, Vol. 6, No. 8, 2006, pp. 1140-1148. http://dx.doi.org/10.1111/j.1567-1364.2006.00097.x

[16] V. Novack, M. Eisinger, A. Frenkel, M. Terblanche, N. K. Adhikari, et al., "The Effects of Statins Therapy on Inflammatory Cytokines in Patients with Bacterial Infections: A Randomized Double-Blind Placebo Controlled Clinical Trial," Intensive Care Medicine, Vol. 35, No. 7, 2009, pp. 1255-1260.

http://dx.doi.org/10.1007/s00134-009-1429-0

[17] K. L. Calisto, B. de Melo Carvalho, E. R. Ropelle, F. C. 
Mittestainer, A. C. A. Camacho, et al., "Atorvastatin Improves Survival in Septic Rats: Effect on Tissue Inflammatory Pathway and on Insulina Signaling," PloS One, Vol. 5, No. 12, 2010, Article ID: e14232.

http://dx.doi.org/10.1371/journal.pone.0014232

[18] I. G. Macreadi, G. Johnson, T. Schlosser and P. I. Macreadi, "Growth Inhibition of Candida Species and Aspergillus fumigatus by Statins," FEMS Microbiology Letters, Vol. 262, No. 1, 2006, pp. 9-13. http://dx.doi.org/10.1111/j.1574-6968.2006.00370.x

[19] C. Westermeyer and I. G. Macreadi, "Simvastatin Reduces Ergosterol Levels, Inhibits Growth and Causes Loss of mtDNA in Candida glabrata," FEMS Yeast Research, Vol. 7, No. 3, 2007, pp. 436-441. http://dx.doi.org/10.1111/j.1567-1364.2006.00194.x

[20] R. W. Thomsen, A. Riss, J. B. Kornum, S. Christensen, S. P. Johnsen, et al., "Preadmission Use of Statins and Outcomes after Hospitalization with Pneumonia," Archives of Internal Medicine, Vol. 168, No. 19, 2008, pp. 2081-2087. http://dx.doi.org/10.1001/archinte.168.19.2081

[21] G. Mells and J. Neuberger, "Reducing the Risks of Cardiovascular Disease in Liver Allograft Recipients," Transplantation, Vol. 83, No. 9, 2007, pp. 1141-1150. http://dx.doi.org/10.1097/01.tp.0000262706.28513.6a

[22] A. P. Liappis, V. L. Kan, C. G. Rochester and G. L. Simon, "The Effect of Statins on Mortality in Patients with Bacteremia," Clinical Infectious Diseases, Vol. 33, No. 8, 2001, pp. 1352-1357. http://dx.doi.org/10.1086/323334

[23] Y. Almog, A. Shefer, V. Novack, N. Maimon, L. Barski, et al., "Prior Statin Therapy Is Associated with a Decreased Rate of Severe Sepsis," Circulation, Vol. 110, 2004, pp. 880-885. http://dx.doi.org/10.1161/01.CIR.0000138932.17956.F1

[24] R. Gupta, L. C. Plantinga, N. E. Fink, M. L. Melamed, J. Coresh, et al., "Statin Use and Hospitalization for Sepsis in Patients with Chronic Kidney Disease," JAMA, Vol. 297, No. 13, 2007, pp. 1455-1464. http://dx.doi.org/10.1001/jama.297.13.1455

[25] E. M. Van De Garde, E. Hak, P. C. Souverein, A. W. Hoes, J. M. van den Bosch and H. G. Leufkens, "Statin Treatment and Reduced Risk of Pneumonia in Patients with Diabetes."

[26] P. Kruger, K. Fitzsimmons, D. Cook, M. Jones and G. Nimmo, "Statin Therapy Is Associated with Feder Deaths in Patients with Bacteraemia," Intensive Care Medicine, Vol. 32, No. 1, 2006, pp. 75-79. http://dx.doi.org/10.1007/s00134-005-2859-y

[27] D. G. Hackam, M. Mandami, P. Li and D. A. Redelmeier, "Statins and Sepsis in Patients with Cardiovascular Disease: A Population-Based Cohort Analysis," Lancet, Vol. 367, No. 9508, 2006, pp. 413-418. http://dx.doi.org/10.1016/S0140-6736(06)68041-0

[28] Y. Almog, V. Novack, M. Eisinger, A. Porath, L. Novack, et al., "The Effect of Statin Therapy on Infection-Related Mortality in Patients with Atherosclerotic Diseases," Critical Care Medicine, Vol. 35, No. 2, 2007, pp. 372-378. http://dx.doi.org/10.1097/01.CCM.0000253397.42079.D5

[29] C. P. Martin, R. L. Talbert, D. S. Burgess and J. I. Peters,
"Effectiveness of Statins in Reducing the Rate of Severe Sepsis: A Retrospective Evaluation," Pharmacotherapy, Vol. 27, No. 1, 2007, pp. 20-26.

[30] P. Kruger, K. Fitzsimmons, D. Cook, M. Jones and G. Nimmo, "Statin Therapy Is Associated with Fewer Deaths in Patients with Bacteraemia," Intensive Care Medicine, Vol. 32, No. 1, 2006, pp. 75-79. http://dx.doi.org/10.1007/s00134-005-2859-y

[31] E. M. Mortensen, M. I. Restrepo, A. Anzueto and J. Pugh, "The Effect of Prior Statin Use on 30-Day Mortality for Patients Hospitalized with Community-Acquired Pneumonia," Respiratory Research, Vol. 6, 2005, p. 82. http://dx.doi.org/10.1186/1465-9921-6-82

[32] H. Schmidt, R. Hennen, A. Keller, et al., "Association of Statin Therapy and Increased Survival in Patients with Multiple Organ Dysfunction Syndrome," Intensive Care Medicine, Vol. 32, No. 8, 2006, pp. 1248-1251. http://dx.doi.org/10.1007/s00134-006-0246-y

[33] S. Al Harbi, H. M. Tamim and Y. N. Marabi, "Association between Statin Therapy and Outcomes in Critically Ill Patients: A Nested Cohorte Study," BMC Clinical Pharmacology, Vol. 11, 2011, p. 12. http://dx.doi.org/10.1186/1472-6904-11-12

[34] F. J. Frost, H. Petersen, K. Tollestrup and B. Skipper, "Influenza and COPD Mortality Protection as Pleiotropic, Dose-Dependent Effects of Statins," Chest, Vol. 131, No. 4, 2007, pp. 1006-1012. http://dx.doi.org/10.1378/chest.06-1997

[35] R. G. Schielenger, D. S. Fedson, S. S. Jick, H. Jick and C. R. Meier, "Statins and the Risk of Pneumonia: A Population-Based, Nested Case-Control Study," Pharmacotherapy, Vol. 27, No. 3, 2007, pp. 325-332.

[36] D. Viasus, D. Gudiol, N. Fernández-Sabé, I. Cabello, G. García-Vidal, et al., "Effect of Statins on Outcomes in Inmunosuppressed Patients with Bloodstream Infections," European Journal of Clinical Microbiology \& Infectious Diseases, Vol. 30, No. 1, 2011, pp. 77-82. http://dx.doi.org/10.1007/s10096-010-1056-2

[37] R. Fernandez, V. J. De Pedro and A. Artigas, "Statin Therapy Prior to ICU Admisión: Protection against Infection or a Severity Marker?" Intensive Care Medicine, Vol. 32, No. 1, 2006, pp. 160-164. http://dx.doi.org/10.1007/s00134-005-2743-9

[38] K. C. Yang, J. Y. Chien, W. K. Tseng, P. R. Hsueh, C. J. $\mathrm{Yu}$ and C. C. Wu, "Statins Do Not Improve Short-Term Survival in an Oriental Population with Sepsis," American Journal of Emergency Medicine, Vol. 25, No. 5, 2007, pp. 494-501. http://dx.doi.org/10.1016/j.ajem.2006.09.011

[39] P. Kopterides, M. E. Falagas, "Statins for Sepsis: A Critical and Updated Review," Clinical Microbiology and Infection, Vol. 15, No. 4, 2009, pp. 325-334. http://dx.doi.org/10.1111/j.1469-0691.2009.02750.x

[40] G. N. Forrest, A. M. Kopack and E. N. Perencevich, "Statins in Candidemia: Clinical Outcomes from a Matched Cohort Study," BMC Infectious Diseases, Vol. 10, 2010, p. 152.

http://dx.doi.org/10.1186/1471-2334-10-152

[41] H. Y. Sun and N. Singh, "Antimicrobial and Immuno- 
modulatory Attributes of Statins: Relevante in Solid-Organ Transplant Recipients," Clinical Infectious Diseases, Vol. 48, No. 6, 2009, pp. 745-755. http://dx.doi.org/10.1086/597039

[42] K. Haldar, "Targeting the Host to Control an Infection Disorder," Archives of Internal Medicine, Vol. 168, No. 19, 2008, pp. 2067-2068. http://dx.doi.org/10.1001/archinte.168.19.2067

[43] P. S. Kruger, N. M. Freir, B. Venkatesh, T. A. Robertson, M. S. Roberts, et al., "A Preliminary Study of Atorvastatin Plasma Concentrations in Critically Ill Patients with Sepsis," Intensive Care Medicine, Vol. 35, No. 4, 2009, pp. 717-721. http://dx.doi.org/10.1007/s00134-008-1358-3

[44] S. Christensen, R. W. Thomsen, M. B. Johansen, L. Pedersen, R. Jensen, et al., "Preadmission Statin Use and One-Year Mortality among Patients in Intensive Care-A Cohorte Study," Critical Care, Vol. 14, No. 2, 2010, p. R29.

[45] S. R. Majumdar, F. A. McAlister, D. T. Eurich, R. S. Padwal and T. J. Marrie, "Statins and Outcomes in Patients Admitted to Hospital with Community Acquired Pneumonia: Population Based Prospective Cohort Study," $B M J$, Vol. 333, 2006, p. 999.

http://dx.doi.org/10.1136/bmj.38992.565972.7C 